\title{
Respiratory Tract Aspiration
}

National Cancer Institute

\section{Source}

National Cancer Institute. Respiratory Tract Aspiration. NCI Thesaurus. Code C83507.

Accidental inhalation of a foreign material into the lungs. 